\title{
The hybrid model of attentional control : new insights into hemispheric asymmetries inferred from TMS research
}

Citation for published version (APA):

Dücker, F., \& Sack, A. T. (2015). The hybrid model of attentional control : new insights into hemispheric asymmetries inferred from TMS research. Neuropsychologia, 74, 21-29. https://doi.org/10.1016/j.neuropsychologia.2014.11.023

Document status and date:

Published: 01/01/2015

DOI:

10.1016/j.neuropsychologia.2014.11.023

Document Version:

Publisher's PDF, also known as Version of record

\section{Document license:}

Taverne

Please check the document version of this publication:

- A submitted manuscript is the version of the article upon submission and before peer-review. There can be important differences between the submitted version and the official published version of record.

People interested in the research are advised to contact the author for the final version of the publication, or visit the DOI to the publisher's website.

- The final author version and the galley proof are versions of the publication after peer review.

- The final published version features the final layout of the paper including the volume, issue and page numbers.

Link to publication

\footnotetext{
General rights rights.

- You may freely distribute the URL identifying the publication in the public portal. please follow below link for the End User Agreement:

www.umlib.nl/taverne-license

Take down policy

If you believe that this document breaches copyright please contact us at:

repository@maastrichtuniversity.nl

providing details and we will investigate your claim.
}

Copyright and moral rights for the publications made accessible in the public portal are retained by the authors and/or other copyright owners and it is a condition of accessing publications that users recognise and abide by the legal requirements associated with these

- Users may download and print one copy of any publication from the public portal for the purpose of private study or research.

- You may not further distribute the material or use it for any profit-making activity or commercial gain

If the publication is distributed under the terms of Article $25 \mathrm{fa}$ of the Dutch Copyright Act, indicated by the "Taverne" license above, 


\title{
The hybrid model of attentional control: New insights into hemispheric asymmetries inferred from TMS research
}

\author{
Felix Duecker ${ }^{a, b, *}$, Alexander T. Sack ${ }^{a, b}$ \\ ${ }^{a}$ Department of Cognitive Neuroscience, Faculty of Psychology and Neuroscience, Maastricht University, Maastricht, The Netherlands \\ ${ }^{\mathrm{b}}$ Maastricht Brain Imaging Center, Maastricht University, Maastricht, The Netherlands
}

\section{A R T I C L E I N F O}

\section{Article history:}

Received 3 October 2014

Received in revised form

17 November 2014

Accepted 19 November 2014

Available online 20 November 2014

Keywords:

Attention

Transcranial magnetic stimulation

Hemispheric asymmetry

Posterior parietal cortex

Frontal eye field

\begin{abstract}
A B S T R A C T
Several competing theories on the mechanisms underlying attentional control have emerged over the years that, despite their substantial differences, all emphasize the importance of hemispheric asymmetries. Transcranial magnetic stimulation (TMS) has proven particularly successful in teasing them apart by selective perturbation of the dorsal and ventral fronto-parietal network. We here critically review the TMS literature and show that hemispheric asymmetries within the dorsal attention network differ between parietal and frontal cortex. Specifically, posterior parietal cortex seems to be characterized by a contralateral bias of each hemisphere and competition between them. In contrast, the right frontal eye field seems to be involved in shifting attention toward both hemifields, whereas left frontal eye field is only involved on shifting attention toward the contralateral hemifield. In the light of presented evidence, we propose to revise the functional-anatomical model originally proposed by Corbetta and Shulman $(2011,2002)$ and introduce a hybrid model of hemispheric asymmetries in attentional control.
\end{abstract} (c) 2014 Elsevier Ltd. All rights reserved.

\section{Introduction}

The voluntary control of attention allows prioritizing those aspects of incoming sensory information that are relevant to us. It therefore constitutes a vital prerequisite for goal-directed behavior and enables us to effectively deal with the abundance of sensory information entering the brain. Already during the beginnings of psychology and neuroscience, the importance of this selection mechanism has been recognized (James, 1890), and there is a wealth of studies investigating the effects of attention on behavior, the functional mechanisms of attentional control, and the underlying neuronal processes (Carrasco, 2011; Corbetta and Shulman, 2002; Desimone and Duncan, 1995; Reynolds and Chelazzi, 2004; Reynolds and Heeger, 2009; Ungerleider and Kastner, 2000).

Similar to the discovery of many other brain functions, neuropsychological findings regarding the behavioral consequences of brain damage have provided first evidence for the involvement of certain brain areas in attentional control and have inspired theories on their functional properties. Especially a neurological syndrome called spatial hemineglect has been very influential. Various models of spatial neglect have been proposed over the years and they have shaped theories on spatial attention control

\footnotetext{
* Corresponding author at: Department of Cognitive Neuroscience, Faculty of Psychology and Neuroscience, Maastricht University, PO Box 616, 6200 MD Maastricht, The Netherlands.

E-mail address: felix.duecker@maastrichtuniversity.nl (F. Duecker).
}

until the present day (Bisiach et al., 1996; Halligan et al., 2003; Milner and McIntosh, 2005; Posner et al., 1987; Robertson, 2001). Spatial hemineglect is caused by lesions to frontal, parietal, or subcortical structures and is characterized by impaired attentional processing within the space contralateral to the lesion's location (Bartolomeo et al., 2012; Corbetta et al., 2005; Duncan et al., 1999; Karnath et al., 2002; Karnath and Rorden, 2012; Mesulam, 1999). Most importantly, the phenomenon of spatial neglect is more common and severe after right hemisphere damage than after left hemisphere damage, suggesting a functional asymmetry of the mechanisms underlying spatial attention (Beis et al., 2004; Suchan et al., 2012). Based on this observation, two competing theories of spatial attention have originally emerged, namely Heilman's hemispatial theory and Kinsbourne's opponent processor model, both accounting for this asymmetry but proposing very different mechanisms (Heilman and Abell, 1980; Heilman and Valenstein, 1979; Kinsbourne, 1977). Despite the many advances in cognitive neuroscience in the last decades, it has been rather difficult to differentiate between these two models with the majority of existing methods. However, transcranial magnetic stimulation (TMS) has proven quite successful in teasing them apart, indeed revealing functional asymmetries between the left and right hemisphere with regard to spatial attention control. With the debate far from being settled, Corbetta and Shulman proposed a functional-anatomical model, strongly supported by neuroimaging data, that offered yet another explanation for the pre-dominance of spatial neglect after right hemisphere damage (Corbetta and Shulman, 
2002; Corbetta and Shulman, 2011). And again, TMS seems to be well-suited to test specific predictions derived from that model.

Here, we first present the three competing models of spatial attention control and lay out their explanatory approach to spatial hemineglect. We then review several lines of research, all based on the application of TMS in healthy volunteers, that have produced critical insights into the mechanisms underlying attentional control. We conclude that each model captures relevant aspects of the mechanisms underlying attentional control, which we here incorporate into one overarching functional-anatomical model of spatial attention control.

\section{Competing models of attentional control}

The pre-dominance of spatial neglect after right hemisphere damage has originally inspired two competing theories of spatial attention control. Both theories assume a functional asymmetry between the two hemispheres but propose very different mechanisms causing it. According to Heilman's hemispatial theory, the right hemisphere is dominant in spatial attention because it mediates attention shifts to both hemifields, whereas the left hemisphere only mediates attention shifts to the right hemifield (Heilman and Abell, 1980; Heilman and Valenstein, 1979). In case of left hemisphere damage, only mild attentional deficits are expected because the right hemisphere can still shift attention to both hemifields thereby compensating for the damaged left hemisphere. Consequently, the ability to shift attention to both hemifields remains largely intact. In case of right hemisphere damage, however, such overlap in function does not exist and functional compensation is impossible because the intact left hemisphere only mediates attention shifts to the right hemifield. Consequently, the ability to shift attention to the left hemifield is lost resulting in spatial neglect of the left hemifield following right hemispheric lesion.

According to Kinsbourne's opponent processor model, each hemisphere causes a natural attention bias to the contralateral hemifield with the rightward bias of the left hemisphere being stronger than the leftward bias of the right hemisphere (Kinsbourne, 1977). Under normal conditions, the two hemispheres are kept in balance due to inter-hemispheric inhibition. In spatial neglect patients, damage to either hemisphere leaves the contralesional intact hemisphere unopposed. As a result of this reduced inhibition, the contralesional hemisphere becomes overactivated and causes an ipsilesional attention bias. Note how impaired attention in one hemifield goes hand in hand with enhanced attention in the opposite hemifield. In case of left hemisphere damage, only mild attentional deficits are expected because the leftward bias of the right hemisphere is relatively small. Consequently, the ability to shift attention to both hemifields remains largely intact. In case of right hemisphere damage, however, the strong rightward bias of the left hemisphere is uncovered and attention is strongly biased to the right hemifield. Consequently, the ability to shift attention to the left hemifield is suppressed resulting in spatial neglect of the left hemifield following right hemispheric lesion.

Finally, Corbetta and Shulman (2002, 2011) have proposed a functional-anatomical model of attentional control that revolves around two distinct but interacting networks comprising frontal and parietal brain areas. On the one hand, they posit a bilateral dorsal fronto-parietal network including the frontal eye field (FEF) and posterior parietal cortex (PPC). This network is directly related to shifts of spatial attention and modulates sensory areas in a topdown way. On the other hand, there is a right-lateralized ventral fronto-parietal network including the temporo-parietal junction (TPJ) and ventral frontal cortex (VFC). This network acts as a circuit breaker of the dorsal network in case an unexpected or salient stimulus occurs that requires reorienting of attention. Importantly, it is argued that lesions to the ventral fronto-parietal network are the primary cause of spatial neglect. The principal idea then is that damage to the ventral network also indirectly affects the dorsal network due to dysfunctional interactions between both networks, resulting in attentional deficits. Because the ventral network is right-lateralized, right hemisphere damage will have a stronger (indirect) effect on the dorsal network than left hemisphere damage, explaining the predominance of spatial hemineglect after right hemisphere lesion.

In general, Heilman's and Kinsbourne's theory make rather global claims regarding hemispheric asymmetries whereas the model proposed by Corbetta and Shulman provides a more detailed functional-anatomical framework of spatial attention control. The latter model is well-supported by neuroimaging data and the relevance of the ventral network in spatial heminegelct seems to fit well with lesion studies. Importantly, even though the dynamics of dorsal and ventral interaction are still largely unknown (but see Corbetta et al., 2008), there are several TMS studies that support the notion that disruption of the ventral network can indeed influence attentional processes. For example, TMS over TPJ has been shown to have effects on visual extinction (Meister et al., 2006), exogenous cueing (Chica et al., 2011), and re-orienting in an attentional capture paradigm (Chang et al., 2013). At present, no strong conclusion can be drawn from this, but it certainly seems promising to further investigate the remote effects of ventral network stimulation on the dorsal network. Having said that, the lateralization of the ventral network to the right hemisphere does not imply that there are no additional hemispheric asymmetries that play a role in attentional control. At least on a conceptual level, the three models described above are not mutually exclusive. For example, hemispheric asymmetries as they are posited by Heilman's hemispatial theory and Kinsbourne's opponent processor model might very well apply to the dorsal fronto-parietal network, and nevertheless, the proposed role of the ventral network in spatial hemineglect might still hold. In the following, we will provide a detailed review of hemispheric asymmetries in the dorsal fronto-parietal network, presenting evidence obtained with various experimental paradigms.

\section{Line bisection}

Among the pen-and-paper tasks that are widely used to assess attentional deficits in clinical settings is the line bisection task that requires patients to mark the perceived midpoint of horizontal lines. Neglect patients typically report a strong deviation from the objective midpoint and, due to neglect of the contralesional hemifield, misplace it toward the ipsilesional hemifield (Albert, 1973). Computerized and adapted versions of this task have been developed that led to the discovery of small attention biases even in healthy volunteers, called pseudoneglect (Jewell and McCourt, 2000). Importantly, it has also been used in several TMS studies, revealing neglect-like attentional deficits after parietal and frontal cortex stimulation (dorsal fronto-parietal network).

To begin with, Fierro et al. (2000) applied trains of high-frequency TMS over left or right posterior parietal cortex (P5/P6 electrode position) time-locked to the presentation of transected lines. The critical finding was that TMS over the right hemisphere caused a rightward shift of attention compared to sham stimulation, whereas TMS over the left hemisphere had no effect. In a follow-up experiment (Brighina et al., 2002), this effect of TMS over right parietal cortex was replicated and extended to frontal areas (F3/F4 electrode position). Again, only TMS over the right hemisphere caused a rightward shift of attention compared to 
sham stimulation, whereas TMS over the left hemisphere had no effect. Finally, these effects were chronometrically explored with single pulse TMS over right parietal or frontal cortex at different time points (Fierro et al., 2001). Somewhat surprisingly, only right parietal cortex stimulation induced an attention bias, specifically at $150 \mathrm{~ms}$ after stimulus onset, but right frontal cortex stimulation was ineffective. However, the absence of a TMS effect in this study might simply be due to the rather coarse spacing of TMS time windows thereby potentially missing the critical phase of frontal cortex involvement in this task.

The studies outlined above failed to induce neglect-like attentional deficits with TMS over the left hemisphere (P5 and F3 electrode position). This is in contrast to later work that also used a line bisection task but slightly different TMS procedures. Szczepanski and Kastner (2013) localized individual TMS target points with fMRI and applied single pulse TMS at $100 \mathrm{~ms}$ after stimulus onset over left intraparietal sulcus (IPS), right IPS, or left and right IPS at the same time. TMS over either hemisphere caused a shift of attention towards the ipsilateral hemifield, but simultaneous stimulation over both hemispheres had no effect. Kim et al. (2005) applied high-frequency offline rTMS over left or right posterior parietal cortex (P3/P4 electrode position) aiming to increase cortical excitability instead of disrupting ongoing processing during task execution. As one might expect, this reversed the direction of effects described above. TMS over either hemisphere caused a shift of attention towards the contralateral hemifield, that is, presumably facilitated attention for that side of space.

These studies provide strong evidence for a hemispheric asymmetry within the dorsal fronto-parietal network. The results for TMS over the right hemisphere generally seem more robust; yet, the inconsistencies between studies for TMS over the left hemisphere might just result from different stimulation sites across studies (P5/P6 versus P3/P4). Overall, this could simply be taken to resemble the predominance of spatial neglect after right hemisphere damage and, in this sense, both Heilman's and Kinsbourne's theory can account for these findings (see previous section). When evaluating these results in more detail, the presence of TMS effects for left parietal cortex and the absence of effects when simultaneously stimulating left and right parietal cortex are most important. According to Kinsbourne's theory, both findings are certainly expected because (1) TMS weakens the bias of the stimulated hemisphere towards the contralateral side of space thereby shifting attention towards the ipsilateral hemifield and (2) the balance between hemispheres largely remains unchanged in case both hemispheres are affected in the same way by TMS. In the light of Heilman's theory, the first type of TMS effects can be explained such that the right hemisphere is processing the line segment in the left hemifield so that functional compensation for TMS-induced disruption of the left hemisphere is impossible. Moreover, Heilman's theory can also explain the second type of findings, as it can be argued that simultaneous stimulation of both hemispheres induces attentional deficits in both hemifields so that the overall line judgment remains unchanged. The latter point also illustrates a major shortcoming of the line bisection task in differentiating both theories: The effects of TMS on attention are not independently assessed in both hemifields, but a relative comparison between both hemifields is obtained instead. This makes it very difficult to unravel the exact effects of TMS on attention.

\section{Visual extinction}

A neurological syndrome that is closely related to spatial neglect is visual extinction. It is characterized by the failure to perceive a stimulus in the contralesional hemifield when a second competing stimulus is simultaneously presented in the ipsilesional hemifield (Riddoch et al., 2009). In a second line of TMS experiments investigating the neural mechanisms of attention, the principle procedure therefore involves a detection task with unilaterally or bilaterally presented visual stimuli. The bilateral condition directly relates to the extinction phenomenon and could be considered somewhat similar to the line bisection task described above because a TMS-induced attention bias can be observed in both cases. However, changes in target detection are assessed in both hemifields independently so that results can be more informative. The unilateral condition probes target detection in the absence of competition and potential effects are therefore conceptually closer to spatial neglect. Even though visual extinction and spatial neglect are dissociable in clinical populations, there is a large co-occurrence of the two syndromes (Vossel et al., 2011). In fact, there is hardly any evidence that TMS can induce clear-cut cases of extinction, that is, disruption of bilateral but intact unilateral stimulus detection, in healthy volunteers.

The first report of TMS-induced extinction stems from PascualLeone et al. (1994), who applied trains of high-frequency TMS over left or right posterior parietal cortex (P3/P4 electrode position) time-locked to stimulus onset. Detection rates in the unilateral condition were not affected by TMS, whereas stimulation of the left and right hemisphere caused extinction of contralateral targets in the bilateral condition. However, performance was almost at ceiling in the unilateral condition, which makes it difficult to induce a TMS effect, whereas the bilateral condition is more challenging and potentially more prone to be affected by TMS. Although to the best of our knowledge, subsequent studies failed to replicate these exact results, the general finding of contralateral disruption is firmly established and has been confirmed repeatedly (Bien et al., 2012; Cazzoli et al., 2009; Dambeck et al., 2006; Hilgetag et al., 2001; Koch et al., 2005), sometimes only after right hemisphere stimulation (Muggleton et al., 2006; Müri et al., 2002), or only for the unilateral condition (Jin and Hilgetag, 2008). For the most part, these findings can be explained by both Heilman's and Kinsbourne's theory along the lines described in the previous section on the line bisection task. However, some of these studies were particularly revealing and provided novel evidence that will be discussed in more detail below.

Probably the most influential study in this context is the one by Hilgetag et al. (2001) who applied low-frequency offline rTMS over left or right posterior parietal cortex (P3/P4 electrode position). As stated above, performance in the bilateral condition was generally worse after TMS compared to baseline with the attention bias shifting towards the stimulated hemisphere, that is, targets were missed more often in the contralateral hemifield. Critically, target detection was enhanced in the ipsilateral hemifield for the unilateral condition. This strongly supports the notion of interhemispheric competition as posited by Kinsbourne, where disruption of one hemisphere leads to disinhibition of the opposite hemisphere so that impaired performance in the contralateral hemifield is accompanied by improved performance in the ipsilateral hemifield. Building on this idea, Dambeck et al. (2006) applied single pulse TMS either over one hemisphere or simultaneously over both left and right posterior parietal cortex (P3/P4 electrode position) at $100 \mathrm{~ms}$ after stimulus onset. As expected, stimulation of one hemisphere disrupted target detection in the contralateral hemifield, but, as in the majority of studies, no enhancement in the ipsilateral hemifield was observed. However, the novel finding was that stimulation of both hemispheres had no effect on target detection, neither in the unilateral nor in the bilateral condition. As above, this strongly supports Kinsbourne's theory where disruption of both hemispheres essentially leaves the balance between them unchanged. Note how this finding resembles the absence of TMS effects after simultaneous stimulation of left and right IPS in the context of the line bisection task 
discussed earlier (Szczepanski and Kastner, 2013). However, much stronger conclusions can be drawn in the present case. While Heilman's theory can explain the result in the bilateral condition just fine, the described findings in the unilateral condition pose a real challenge because target detection should be impaired in both hemifields after stimulation of the left and right hemisphere.

Taken together, these experiments provide critical evidence in favor of Kinsbourne's theory and they are at odds with Heilman's theory. However, replication of these findings is needed in order to further strengthen this conclusion since the majority of studies failed to observe an ipsilateral enhancement in the unilateral condition. It is also important to note that all the studies mentioned above applied TMS over posterior parietal cortex, so conclusions are not necessarily generalizable to other parts of dorsal fronto-parietal network where this paradigm has never been applied.

\section{Distractor interference}

The phenomenon of visual extinction nicely exemplifies the critical role of attention as a selection mechanism when there is competition between multiple visual inputs. There is a closely related class of experiments that use task-irrelevant distractors that interfere with the processing of a target stimulus. The extent of distractor interference is a measure of attentional selection. In general, TMS studies using such paradigms obtained results pointing in the same direction as the visual extinction studies described above.

Chambers et al. (2006) applied trains of high-frequency TMS over several anatomically defined sub-regions of right parietal cortex time-locked to stimulus onset. TMS selectively influenced reaction times when the target and distractor were in opposite hemifields, whereas no TMS effect was observed when both stimuli were presented in the same hemifield. More specifically, stimulation of the supramarginal gyrus and superior parietal lobule (but not the angular gyrus) led to enhanced performance in the ipsilateral hemifield. Similarly, Hung et al. (2005) used a partial report paradigm where a target stimulus was either presented alone, or accompanied by a second target or non-target in the same or opposite hemifield. Trains of high-frequency TMS were applied over left or right posterior parietal cortex and, as above, TMS effects were only found for visual displays that contained competing stimuli in both hemifields. Importantly, task performance was only influenced by right parietal cortex stimulation with decreased accuracy in the left hemifield and increased accuracy in the right hemifield.

As in previous sections, TMS over posterior parietal cortex led to enhanced performance in the ipsilateral hemifield seemingly supporting Kinsbourne's theory. In the context of distractor interference, however, interpretation of this finding is somewhat complicated by potential TMS effects on both the target and distractor. On the one hand, TMS over right PPC could enhance performance in the right hemifield simply by disrupting processing of a distractor in the left hemifield. On the other hand, right PPC stimulation could release the left hemisphere from inter-hemispheric inhibition thereby enhancing target processing in the right hemifield. In our view, only the latter interpretation lends support to Kinsbourne's theory, but it seems difficult to decide between these two alternatives. Having said that, the very fact that distractors in one hemifield influence target detection in the opposite hemifield strongly suggests that there is competition between hemispheres and the evidence outlined above certainly does not favor Heilman's theory.

Finally, Hung et al. (2011) conducted a second experiment with the very same partial report paradigm but this time applying TMS over frontal cortex. As above, only right hemisphere stimulation had an effect on task performance, but the pattern of results obtained with TMS over right FEF was strikingly different from TMS over right PPC. Task performance was impaired in both hemifields supporting Heilman's theory, which states that the right hemisphere mediates attention shifts to both hemifields. This is obviously in stark contrast to findings of ipsilateral enhancement with TMS over right PPC and at odds with Kinsbourne's theory. It therefore appears that hemispheric asymmetries in attentional control might not be the same across different nodes of the dorsal fronto-parietal network.

\section{Spatial orienting paradigm}

Arguably the most popular way to investigate attentional processes is the spatial orienting paradigm that involves an explicit experimental manipulation of the attended hemifield (Posner, 1980; Posner et al., 1980). Typically, a central symbolic cue provides information about the location of an upcoming target stimulus allowing preparatory attention shifts. Although often omitted, the inclusion of non-informative neutral cues conceptually serves as an important baseline to assess task performance in the absence of spatial expectancies. Compared to neutral cues, valid cues are associated with faster reaction times due to orienting of attention towards the correctly cued location (attentional benefits), whereas invalid cues are associated with slower reaction times due to reorienting of attention from the falsely cued location to the actual target location (attentional costs). This separation of orienting and reorienting of attention is impossible if the neutral condition is missing. In such cases, the reaction time difference between valid and invalid trials is commonly used as an outcome measure (often referred to as cueing or validity effect), confounding these two processes. As will be shown below, these orienting paradigms have produced critical insights into functional asymmetries within the dorsal fronto-parietal network even though they can be difficult to interpret at times, in part due to their increased complexity compared to the paradigms discussed thus far.

Among the first to investigate the effects of TMS on a spatial orienting paradigm were Grosbras and Paus (2002) who applied single pulse TMS over left or right FEF during the cue-target interval. Somewhat surprisingly and in disagreement with the original hypothesis, TMS did not disrupt orienting of attention but affected performance across all cueing conditions. Specifically, TMS over right FEF mostly decreased reaction times for targets in both hemifields, whereas effects of TMS over left FEF were restricted to the right hemifield. Obviously, these results are very interesting and do have a bearing on the present discussion, but it is important to note that they reflect a general (albeit hemifieldspecific) perceptual change rather than a selective modulation of attentional processes. This interpretation received further support by a follow-up study where TMS over FEF improved detection of near-threshold stimuli in the absence of spatial cues (Grosbras and Paus, 2003). As above, right FEF stimulation caused a bilateral enhancement, whereas left FEF stimulation only had an effect in the contralateral hemifield. Similarly, Chanes et al. (2012) found increased perceptual sensitivity in both hemifields when a TMS pulse over right FEF preceded target appearance. It is important to note that these cases of TMS-induced enhancement are very different from those discussed in previous sections. In the latter case, the pattern of results was in agreement with a mechanism of inter-hemispheric inhibition with enhancement occurring in the ipsilateral hemifield. Here, the pattern of results is completely different and most likely reflects a top-down effect on visual cortex, which facilitates perceptual processes. These examples thus 
illustrate how difficult it can be to dissociate perceptual from attentional processes when applying TMS during task execution. We have recently used a virtual lesion approach by applying continuous theta burst stimulation over left or right FEF prior to task execution, which turned out to be more successful in selectively disrupting attentional processes (Duecker et al., 2013). The key finding was that attentional benefits were reduced in both hemifields after right FEF stimulation, whereas left FEF stimulation only reduced attentional benefits in the contralateral hemifield. Obviously, this pattern of results mirrors the findings outlined above, but, critically, performance on neutral trials was entirely unaffected by TMS. These results therefore provide strong direct evidence for a functional asymmetry between hemispheres when looking at the mechanisms underlying voluntary shifts of spatial attention within frontal cortex. Taken together, all these studies strongly suggest that the right FEF is involved in shifting attention across the entire visual field supporting Heilman's theory, and, again, this pattern of results is unexpected in the light of Kinsbourne's theory.

There are several studies that applied TMS over FEF during task execution but did not include neutral trials. As explained above, these studies can be difficult to interpret but potential hemifieldspecific effects are still of interested for the present discussion. To begin with, Chanes et al. (2012) applied single pulse TMS over right FEF during the cue-target interval and found enhanced perceptual sensitivity in both hemifields. Importantly, this facilitation was only observed for valid trials, whereas invalid trials were unaffected suggesting that TMS amplified the effects of attention on perceptual processes. In the context of studies with left FEF stimulation, Smith et al. (2005) applied trains of high-frequency TMS around cue onset and found a decreased cueing effect in the right hemifield. Because no effect on valid trials was observed, the authors argued that left FEF disruption eliminated attentional costs presumably due to a lack of inhibition of the right hemifield after leftward cues. In contrast, Chica et al. (2014) stimulated left FEF during the cue-target interval and found an increased cueing effect in the left hemifield. The authors interpreted this as a facilitatory effect in line with other cases of TMS-induced ipsilateral enhancement that are also discussed in this review (e.g. Hilgetag et al., 2001; Thut et al., 2005). A closer look at the data, however, suggests a possible alternative interpretation. As has been noted before, the cueing effect combines attentional benefits and costs into one outcome measure and an increased cueing effect can thus reflect a change in either one of them. In the present case, performance on both valid and invalid trials decreased, with the effect being stronger for the invalid condition. Consequently, the difference between these conditions increased, which, in our view and in the context of the here presented models of attention control, does not imply a real enhancement of attention. Taken together, these studies therefore further strengthen the case for Heilman's theory within frontal cortex with the effects of right FEF stimulation being highly consistent across studies. For left FEF stimulation, the general picture is not as clear-cut but this might be accounted for by the methodological concerns pointed out before.

Finally, the effects of TMS over parietal cortex on spatial orienting have hardly been investigated. Thut et al. (2005) applied $1 \mathrm{~Hz}$ rTMS over right PPC (P4 electrode position) and found a general impairment of target detection following leftward cues but a very specific enhancement of target detection in the right hemifield following rightward cues. Importantly, in the latter case, no performance change in the neutral condition was observed. This resembles the pattern of results obtained with other experimental paradigms using TMS over PPC.

\section{Multimodal approaches with TMS}

We have presented several experimental paradigms and shown how TMS affects task performance on the behavioral level. For the most part, however, it remains unknown how the observed behavioral effects can be explained by TMS-induced changes in the brain. For that reason, it is highly desirable to assess the neural correlates of TMS effects, which can be achieved by combining TMS with other methods. This adds a further dimension to the present discussion and connects TMS research with existing neuroimaging and neurophysiological data.

Attention is often conceptualized as a top-down mechanism that modulates brain activity in sensory cortices thereby biasing how incoming sensory information is processed (Desimone and Duncan, 1995). Interestingly, TMS can be used to assess cortical excitability in the visual system by determining the stimulation intensity necessary to evoke faint visual percepts called phosphenes (Marg and Rudiak, 1994). Using this approach, it has been shown that cortical excitability in visual cortex is modulated by attention (Bestmann et al., 2007). As expected, the phosphene threshold in one hemisphere was lower when attention was directed towards the corresponding hemifield compared to the opposite hemifield. Extending this work, Silvanto et al. (2006) applied single pulse TMS over left or right FEF, hypothesizing that TMS would modulate excitability in visual cortex just as an experimental manipulation of attention does. Indeed, right FEF stimulation was found to decrease the phosphene threshold in both hemifields, whereas left FEF stimulation only decreased the phosphene threshold in the left hemisphere (i.e. right hemifield). Finally, Silvanto et al. (2009) applied triple-pulse TMS either over one hemisphere or simultaneously over both left and right PPC. As in similar work discussed before, unilateral stimulation of PPC caused a change in cortical excitability (albeit in both hemispheres) but bilateral stimulation abolished these effects. These studies show that TMS over the dorsal fronto-parietal network can influence visual cortex analogous to top-down modulations by attentional orienting. Moreover, such top-down effects on visual cortex potentially explain the facilitatory effects often observed when applying TMS during task execution, next to explanatory accounts based on inter-hemispheric inhibition.

The notion that TMS is capable of modulating activity in visual cortex received even stronger support from a series of studies that applied TMS while simultaneously measuring BOLD activity changes with fMRI. Ruff et al. (2006, 2009) applied TMS over left or right FEF and observed remote effects on bilateral visual cortex. Specifically, a BOLD decrease for the representation of the central part of the visual field was observed with stimulation over left and right FEF, whereas a BOLD increase for the representation of the peripheral part of the visual field was only observed after right FEF stimulation. Yet another hemispheric asymmetry was found when applying TMS over left or right PPC (Ruff et al., 2008, 2009). Here, right PPC stimulation had an effect on bilateral visual cortex, whereas left PPC stimulation had no top-down effect on those regions. Taken together, these studies further support the existence of hemispheric asymmetries within the dorsal frontoparietal network and indicate that these asymmetries are not the same for frontal and parietal cortex. It has to be acknowledged that the pattern of results observed in these combined TMS/fMRI studies does not directly match the behavioral findings discussed in previous sections. But given that these remote effects of TMS on visual cortex were obtained during passive viewing, it may not come as a surprise that they do not correspond to behavioral changes in the context of active task execution. Even more promising results were obtained by Blankenburg et al. (2010) who investigated the effects of right parietal TMS in combination with an experimental manipulation of attention. As above, TMS had 
remote effects on visual cortex and, more importantly, this topdown modulation was dependent on the locus of attention. Specifically, the BOLD signal in the right hemisphere increased when attention was directed towards the left hemifield, whereas a decrease was observed when attention was directed towards the right hemifield. Moreover, the BOLD signal increase in the right hemisphere was accompanied by a BOLD signal decrease in the left hemisphere. Even though these BOLD signal changes are difficult to interpret, the presence of opposite effects in both hemispheres is indicative of inter-hemispheric inhibition in parietal cortex. Similarly, Heinen et al. (2011) provided strong evidence for interhemispheric effects during right angular gyrus stimulation that were dependent on the attentional state and target location in the context of an exogenous cueing task. Without going into further details here, these studies exemplify the potential of combining TMS and fMRI to reveal the neural underpinnings of TMS-induced behavioral changes. The results thus far are encouraging but connecting the experimental paradigms discussed in this review with multimodal studies has only just begun.

Finally, there is an abundance of neurophysiological evidence based on EEG and MEG data showing that attention modulates evoked potentials in sensory areas (Hillyard and Anllo-Vento, 1998) and that neuronal oscillations in the alpha frequency band in occipital-parietal cortex play a key role in attentional selection (Jensen et al., 2014). The combination of TMS and EEG has revealed that stimulation of the dorsal fronto-parietal network affects these neural correlates of attention. As these studies have been reviewed recently (Taylor and Thut, 2012), we will not go into great detail here but will briefly mention the main findings. Most importantly, TMS over both frontal and parietal nodes of the dorsal network has an effect on the EEG responses in the context of attention tasks (Capotosto et al., 2009, 2011, 2012; Sauseng et al., 2011; Taylor et al., 2007). Moreover, the typical changes in posterior alpha power that can be observed when attention is shifted towards one hemifield are often attenuated with TMS along with corresponding behavioral changes. And lastly, TMS over parietal cortex can even be used to entrain alpha oscillations (Thut et al., 2011) and these TMS-induced changes in alpha power have been shown to be behaviorally relevant (Romei et al., 2010) with right PPC stimulation impairing visual detection in the left hemifield but enhancing visual detection in the right hemifield.

\section{Hemispheric asymmetries in the dorsal fronto-parietal network}

When considering the research lines discussed here collectively, there are several consistent observations that have strong implications for functional-anatomical models of attention control. Most importantly, there is evidence for right-hemispheric dominance in attentional control and the reviewed literature shows that asymmetries between the left and right hemisphere are not the same for parietal and frontal cortex. These points will be described one by one in the following paragraphs.

To begin with, stimulation of the right dorsal network (PPC and FEF) led to changes in task performance in a vast majority of studies, whereas stimulation of the left dorsal network sometimes failed to have an effect. This general asymmetry is at least indicative for right hemisphere dominance in attentional control, as suggested by Mesulam (1981). However, it is important to keep in mind that negative results should rarely be considered as evidence of absence, particularly in TMS research (De Graaf and Sack, 2011). Given that most studies applied TMS with suboptimal TMS coil positioning approaches, it might very well be that inaccuracies in localization contribute to such null-results. As the number of TMS studies increases, such methodological issues might eventually be answered by comparing the robustness of effects depending on the TMS coil positioning approach.

For parietal cortex, the pattern of results is in strong agreement with Kinsbourne's opponent processor model. In the majority of studies, unilateral PPC stimulation in either hemisphere impaired task performance in the contralateral hemifield. Moreover, there are two lines of evidence that suggest that left and right PPC competitively interact via inter-hemispheric inhibition. First, bilateral PPC stimulation has consistently been found to not alter task performance when unilateral stimulation conditions were effective. This shows that left and right PPC are jointly involved in attentional control and that it is their relative contribution that determines performance. Second, there are several studies that observed an ipsilateral enhancement after PPC stimulation. While this is in agreement with a contralateral release from inhibition, we have argued that task-related explanations can account for this effect in some cases. Further investigations of this effect with appropriate experimental designs therefore seem highly desirable. Still, these findings are clearly at odds with Heilman's theory, and Kinsbourne's theory can fully account for the unilateral and bilateral stimulation effects.

For frontal cortex, the pattern of results is in strong agreement with Heilman's hemispatial theory. Right FEF stimulation has consistently been found to affect task performance in both hemifield, whereas left FEF stimulation only affected the contralateral hemifield. Importantly, the existing TMS literature provides no evidence for inter-hemispheric competition as observed in parietal cortex. Another interesting difference to TMS effects observed with PPC stimulation is that TMS over FEF often led to a general enhancement of perceptual sensitivity. It therefore seems that FEF and PPC have different functional roles and/or TMS over these regions has differential effects on the entire functional network.

\section{The hybrid model of attentional control}

The main outcome of the present review is that both Heilman's hemispatial theory and Kinsbourne's opponent processor model capture relevant aspects of the mechanisms underlying attentional control. Specifically, each theory appears to apply to distinct parts of the dorsal attention network. We therefore propose to revise the functional-anatomical model originally proposed by Corbetta and Shulman $(2002,2011)$ and introduce a hybrid model of attentional control that incorporates two distinct hemispheric asymmetries within the dorsal fronto-parietal network (Fig. 1). In agreement with Kinsbourne's theory, parietal regions within the dorsal attention network are characterized by inter-hemispheric competition, with each hemisphere biasing attention toward the contralateral hemifield. In agreement with Heilman's theory, frontal regions within the dorsal attention network are characterized by righthemispheric dominance, with the right hemisphere mediating attention shifts to both hemifields and the left hemisphere mediating attention shifts only to the contralateral hemifield. Regarding the ventral fronto-parietal network, its functional role and lateralization to the right hemisphere remain a critical aspect of this model, as suggested by Corbetta and Shulman (2002, 2011). Finally, returning to the initial issue of pre-dominance of spatial neglect after right hemisphere damage, we have presented compelling evidence for hemispheric asymmetries within the dorsal fronto-parietal network and we therefore argue that these region-specific asymmetries play a distinctive role in spatial neglect.

\section{Future perspectives}

The hybrid model of attentional control attributes distinct hemispheric asymmetries to frontal and parietal parts of the 


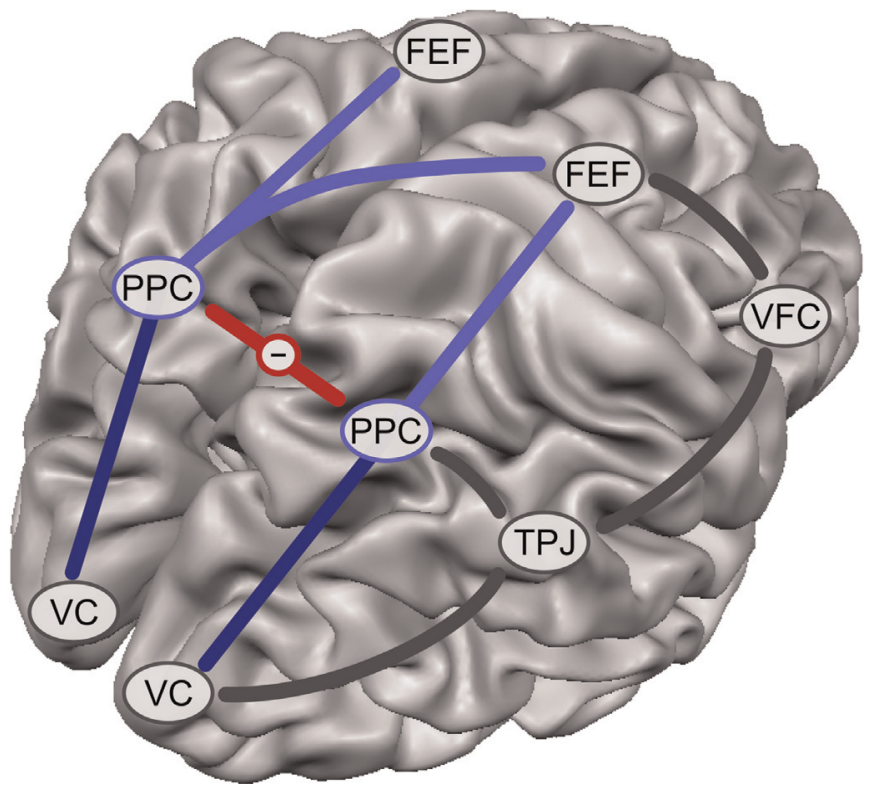

Fig. 1. A schematic representation of our revised model of attentional control. Importantly, we propose two distinct hemispheric asymmetries within the dorsal fronto-parietal network. For parietal cortex, there is top-down modulation of visual cortex within each hemisphere (dark blue lines) and inter-hemispheric competition (red line). For frontal cortex, the right hemisphere is involved in mediating attention in both hemifields by influencing parietal cortex and/or visual cortex whereas the left hemisphere is only involved in mediating attention to the right hemifield (light blue lines). The ventral fronto-parietal network is shown as well for completeness. $\mathrm{VC}=$ visual cortex, $\mathrm{PPC}=$ posterior parietal cortex, $\mathrm{FEF}=$ frontal eye field, TPJ = temporo-parietal junction, and $\mathrm{VFC}=$ ventral frontal cortex. (For interpretation of the references to color in this figure legend, the reader is referred to the web version of this article.)

dorsal fronto-parietal network. For the purpose of the present review, this rather coarse anatomical division was sufficient. However, there is strong evidence from neuroimaging studies that PPC can be subdivided into multiple spatial maps of the contralateral visual field that seem to have different functional roles (Hagler Jr. et al., 2007; Sereno et al., 2001; Silver and Kastner, 2009). This poses the question whether or not Kinsbourne's opponent processor model applies to PPC in general or only to some of these different PPC sub-regions. Given the spatial resolution of TMS, it is in principle possible to target sub-regions within PPC in each hemisphere and to investigate hemispheric asymmetries on a smaller spatial scale than discussed here. Similarly, spatial maps have also been identified in frontal cortex, again, with a clear preference for the contralateral side of space (Hagler Jr. et al., 2007; Hagler Jr. and Sereno, 2006; Silver and Kastner, 2009). Given the strong evidence that right FEF mediates attention shifts across the entire visual field, it remains to be seen how these two findings can be reconciled.

Our discussion of hemispheric asymmetries was based on various experimental paradigms that each provided very consistent evidence leading to the hybrid model of attentional control. While all studies collectively are very compelling, there remain open issues that have not been addressed yet. To begin with, line bisection and visual extinction paradigms were almost exclusively used in combination with parietal cortex stimulation whereas the opposite holds for spatial orienting paradigms that were mostly used in combination with frontal cortex stimulation. Based on the hybrid model of attentional control, there are straight-forward predictions how performance on these tasks should be affected when stimulating different nodes of the dorsal fronto-parietal network. For example, simultaneous stimulation of left and right frontal cortex has not been tried yet and, unlike parietal cortex stimulation, should result in changes in task performance. Another highly interesting issue is the time course of frontal and parietal involvement in attentional control. Chronometric TMS studies are still very rare in this area of research but might be extremely valuable for better understanding the dynamics of information processing in the dorsal and ventral fronto-parietal network.

Finally, TMS is a promising therapeutic tool in patients with attentional deficits. Clinical research thus far focused on parietal cortex stimulation but interventions at other stimulation sites could also be promising. Importantly, our model strongly suggests that TMS protocols that are effective over parietal cortex should not simply be translated to frontal cortex. For example, a common rationale in stroke rehabilitation is based on the concept of interhemispheric competition, namely applying inhibitory TMS protocols over the healthy hemisphere in order to reduce the attention bias towards the ipsilesional visual field (Cazzoli et al., 2010; Fierro et al., 2006; Hesse et al., 2011; Sparing et al., 2009). Based on our hybrid model, this approach would be ineffective or potentially even counterproductive over frontal cortex due to its different functional organization.

\section{Acknowledgments}

This work was supported by the European Research Council under the European Union's Seventh Framework Programme (FP7/ 2007-2013)/ERC Grant agreement (263472, awarded to A.T.S.).

\section{References}

Albert, M.L., 1973. A simple test of visual neglect. Neurology 23 (6), 658-664. Bartolomeo, P., Thiebaut De Schotten, M., Chica, A.B., 2012. Brain networks of visuospatial attention and their disruption in visual neglect. Front. Hum. Neurosci. 6, 110. http://dx.doi.org/10.3389/fnhum.2012.00110.

Beis, J-M, Keller, C., Morin, N., Bartolomeo, P., Bernati, T., Chokron, S., Leclercq, M., Louis-Dreyfus, A., Marchal, F, Martin, Y., Perennou, D., Pradat-Diehl, P., Prairial, C., Rode, G., Rousseaux, M., Samuel, C., Sieroff, E., Wiart, L., Azouvi, P., 2004. French Collaborative Study Group on Assessment of Unilateral Neglect, Right spatial neglect after left hemisphere stroke: qualitative and quantitative study. Neurology 63 (9), 1600-1605. http://dx.doi.org/10.1212/01.wnl.0000142967.60579.32.

Bestmann, S., Ruff, C.C., Blakemore, C., Driver, J., Thilo, K.V., 2007. Spatial attention changes excitability of human visual cortex to direct stimulation. Curr. Biol. 17 (2), 134-139. http://dx.doi.org/10.1016/j.cub.2006.11.063.

Bien, N., Goebel, R., Sack, A.T., 2012. Extinguishing extinction: hemispheric differences in the modulation of TMS-induced visual extinction by directing covert spatial attention. J. Cognit. Neurosci. 24 (4), 809-818. http://dx.doi.org/10.1162/ jocn_a_00179.

Bisiach, E., Pizzamiglio, L., Nico, D., Antonucci, G., 1996. Beyond unilateral neglect. Brain 119 (3), 851-857. http://dx.doi.org/10.1093/brain/119.3.851.

Blankenburg, F., Ruff, C.C., Bestmann, S., Bjoertomt, O., Josephs, O., Deichmann, R., Driver, J., 2010. Studying the role of human parietal cortex in visuospatial attention with concurrent TMS-fMRI. Cereb. Cortex 20 (11), 2702-2711. http://dx. doi.org/10.1093/cercor/bhq015.

Brighina, F., Bisiach, E., Piazza, A., Oliveri, M., La Bua, V., Daniele, O., Fierro, B., 2002. Perceptual and response bias in visuospatial neglect due to frontal and parietal repetitive transcranial magnetic stimulation in normal subjects. Neuroreport 13 (18), 2571-2575.

Capotosto, P., Babiloni, C., Romani, G.L., Corbetta, M., 2009. Frontoparietal cortex controls spatial attention through modulation of anticipatory alpha rhythms. J. Neurosci. 29 (18), 5863-5872. http://dx.doi.org/10.1523/JNEUROSCI.053909.2009.

Capotosto, P., Babiloni, C., Romani, G.L., Corbetta, M., 2011. Differential contribution of right and left parietal cortex to the control of spatial attention: a simultaneous EEG-rTMS study. Cereb. Cortex bhr127, 446-454. http://dx.doi.org/ 10.1093/cercor/bhr127.

Capotosto, P., Corbetta, M., Romani, G.L., Babiloni, C., 2012. Electrophysiological correlates of stimulus-driven reorienting deficits after interference with right parietal cortex during a spatial attention task: a TMS-EEG study. J. Cognit. Neurosci. 24 (12), 2363-2371. http://dx.doi.org/10.1162/jocn_a_00287.

Carrasco, M., 2011. Visual attention: the past 25 years. Vis. Res. 51 (13), 1484-1525. http://dx.doi.org/10.1016/j.visres.2011.04.012.

Cazzoli, D., Müri, R., Hess, C., Nyffeler, T., 2009. Horizontal and vertical dimensions of visual extinction: a theta burst stimulation study. Neuroscience 164 (4), 1609-1614. http://dx.doi.org/10.1016/j.neuroscience.2009.09.044. 
Cazzoli, D., Müri, R.M., Hess, C.W., Nyffeler, T., 2010. Treatment of hemispatial neglect by means of rTMS - a review. Restor. Neurol. Neurosci. 28 (4), 499-510. http://dx.doi.org/10.3233/RNN-2010-0560.

Chambers, C.D., Stokes, M.G., Janko, N.E., Mattingley, J.B., 2006. Enhancement of visual selection during transient disruption of parietal cortex. Brain Res. 1097 (1), 149-155. http://dx.doi.org/10.1016/j.brainres.2006.04.084.

Chanes, L., Chica, A.B., Quentin, R., Valero-Cabré, A., 2012. Manipulation of pretarget activity on the right frontal eye field enhances conscious visual perception in humans. PloS One 7 (5), e36232. http://dx.doi.org/10.1371/journal pone.0036232.

Chang, C.F., Hsu, T.Y., Tseng, P., Liang, W.K., Tzeng, O.J., Hung, D.L., Juan, C.H., 2013. Right temporoparietal junction and attentional reorienting. Hum. Brain Map. 34 (4), 869-877. http://dx.doi.org/10.1002/hbm.21476.

Chica, A.B., Bartolomeo, P., Valero-Cabré, A., 2011. Dorsal and ventral parietal contributions to spatial orienting in the human brain. J. Neurosci. 31 (22), 8143-8149. http://dx.doi.org/10.1523/JNEUROSCI.5463-10.2010.

Chica, A.B., Valero-Cabré, A., Paz-Alonso, P.M., Bartolomeo, P., 2014. Causal contributions of the left frontal eye field to conscious perception. Cereb. Cortex 24 (3), 745-753. http://dx.doi.org/10.1093/cercor/bhs357.

Corbetta, M., Kincade, M.J., Lewis, C., Snyder, A.Z., Sapir, A., 2005. Neural basis and recovery of spatial attention deficits in spatial neglect. Nat. Neurosci. 8 (11), 1603-1610. http://dx.doi.org/10.1038/nn1574.

Corbetta, M., Patel, G., Shulman, G.L., 2008. The reorienting system of the human brain: from environment to theory of mind. Neuron 58 (3), 306-324. http://dx. doi.org/10.1016/j.neuron.2008.04.017.

Corbetta, M., Shulman, G.L., 2002. Control of goal-directed and stimulus-driven attention in the brain. Nat. Rev. Neurosci. 3 (3), 201-215. http://dx.doi.org/ $10.1038 /$ nrn755.

Corbetta, M., Shulman, G.L., 2011. Spatial neglect and attention networks. Annu. Rev. Neurosci. 34 (1), 569-599. http://dx.doi.org/10.1146/annurev-neuro061010-113731.

Dambeck, N., Sparing, R., Meister, I.G., Wienemann, M., Weidemann, J., Topper, R., Boroojerdi, B., 2006. Interhemispheric imbalance during visuospatial attention investigated by unilateral and bilateral TMS over human parietal cortices. Brain Res. 1072 (1), 194-199. http://dx.doi.org/10.1016/j.brainres.2005.05.075.

De Graaf, T., Sack, A., 2011. Null results in TMS: from absence of evidence to evidence of absence. Neurosci. Biobehav. Rev. 35 (3), 871-877. http://dx.doi.org 10.1016/j.neubiorev.2010.10.006.

Desimone, R., Duncan, J., 1995. Neural mechanisms of selective visual attention. Annu. Rev. Neurosci. 18 (1), 193-222.

Duecker, F., Formisano, E., Sack, A.T., 2013. Hemispheric differences in the voluntary control of spatial attention: direct evidence for a right-hemispheric dominance within frontal cortex. J. Cognit. Neurosci. 25 (8), 1332-1342. http://dx.doi.org/ 10.1162/jocn_a_00402.

Duncan, J., Bundesen, C., Olson, A., Humphreys, G., Chavda, S., Shibuya, H., 1999. Systematic analysis of deficits in visual attention. J. Exp. Psychol.: Gen. 128 (4), 450-478. http://dx.doi.org/10.1037/0096-3445.128.4.450.

Fierro, B., Brighina, F., Bisiach, E., 2006. Improving neglect by TMS. Behav. Neurol. 17 (3-4), http://dx.doi.org/10.1155/2006/465323.

Fierro, B., Brighina, F., Oliveri, M., Piazza, A., La Bua, V., Buffa, D., Bisiach, E., 2000. Contralateral neglect induced by right posterior parietal rTMS in healthy subjects. Neuroreport 11 (7), 1519-1521.

Fierro, B., Brighina, F., Piazza, A., Oliveri, M., Bisiach, E., 2001. Timing of right parietal and frontal cortex activity in visuo-spatial perception: a TMS study in normal individuals. Neuroreport 12 (11), 2605-2607.

Grosbras, M.-H., Paus, T., 2002. Transcranial magnetic stimulation of the human frontal eye field: effects on visual perception and attention. J. Cognit. Neurosci. 14 (7), 1109-1120. http://dx.doi.org/10.1162/089892902320474553.

Grosbras, M.H., Paus, T., 2003. Transcranial magnetic stimulation of the human frontal eye field facilitates visual awareness. Eur. J. Neurosci. 18 (11), 3121-3126. http://dx.doi.org/10.1111/j.1460-9568.2003.03055 x.

Hagler Jr, D.J., Riecke, L., Sereno, M.I., 2007. Parietal and superior frontal visuospatial maps activated by pointing and saccades. NeuroImage 35 (4), 1562-1577. http://dx.doi.org/10.1016/j.neuroimage.2007.01.033.

Hagler Jr, D.J., Sereno, M.I., 2006. Spatial maps in frontal and prefrontal cortex. Neurolmage 29 (2), 567-577. http://dx.doi.org/10.1016/j. neuroimage.2005.08.058.

Halligan, P.W., Fink, G.R., Marshall, J.C., Vallar, G., 2003. Spatial cognition: evidence from visual neglect. Trends Cognit. Sci. 7 (3), 125-133. http://dx.doi.org/ 10.1016/S1364-6613(03)00032-9.

Heilman, K.M., Abell, T.V.D., 1980. Right hemisphere dominance for attention. Neurology 30 (3), 327.

Heilman, K.M., Valenstein, E., 1979. Mechanisms underlying hemispatial neglect. Ann. Neurol. 5 (2), 166-170.

Heinen, K., Ruff, C.C., Bjoertomt, O., Schenkluhn, B., Bestmann, S., Blankenburg, F., Chambers, C.D., 2011. Concurrent TMS-fMRI reveals dynamic interhemispheric influences of the right parietal cortex during exogenously cued visuospatial attention. Eur. J. Neurosci. 33 (5), 991-1000. http://dx.doi.org/10.1111/j.14609568.2010.07580.x.

Hesse, M.D., Sparing, R., Fink, G.R., 2011. Ameliorating spatial neglect with noninvasive brain stimulation: from pathophysiological concepts to novel treatment strategies. Neuropsychol. Rehabil. 21 (5), 676-702. http://dx.doi.org/ 10.1080/09602011.2011.573931.

Hilgetag, C.C., Théoret, H., Pascual-Leone, A., 2001. Enhanced visual spatial attention ipsilateral to rTMS-induced 'virtual lesions' of human parietal cortex. Nat. Neurosci. 4 (9), 953-957. http://dx.doi.org/10.1038/nn0901-953.
Hillyard, S.A., Anllo-Vento, L., 1998. Event-related brain potentials in the study of visual selective attention. Proc. Natl. Acad. Sci. 95 (3), 781-787.

Hung, J., Driver, J., Walsh, V., 2005. Visual selection and posterior parietal cortex: effects of repetitive transcranial magnetic stimulation on partial report analyzed by Bundesen's theory of visual attention. J. Neurosci. 25 (42), 9602-9612. http://dx.doi.org/10.1523/JNEUROSCI.0879-05.2005.

Hung, J., Driver, J., Walsh, V., 2011. Visual selection and the human frontal eye fields: effects of frontal transcranial magnetic stimulation on partial report analyzed by Bundesen's theory of visual attention. J. Neurosci. 31 (44), 15904-15913. http://dx.doi.org/10.1523/JNEUROSCI.2626-11.2011.

James, W., 1890. The Principles of Psychology. Henry Holt, New York.

Jensen, O., Gips, B., Bergmann, T.O., Bonnefond, M., 2014. Temporal coding organized by coupled alpha and gamma oscillations prioritize visual processing. Trends Neurosci., 357-369. http://dx.doi.org/10.1016/j.tins.2014.04.001.

Jewell, G., McCourt, M.E., 2000. Pseudoneglect: a review and meta-analysis of performance factors in line bisection tasks. Neuropsychologia 38 (1), 93-110 (Pseudoneglect: a review and meta-analysis of performance factors in line bisection tasks).

Jin, Y., Hilgetag, C.C., 2008. Perturbation of visuospatial attention by high-frequency offline rTMS. Exp. Brain Res. 189 (1), 121-128. http://dx.doi.org/10.1007/ s00221-008-1449-y.

Karnath, H.O., Himmelbach, M., Rorden, C., 2002. The subcortical anatomy of human spatial neglect: putamen, caudate nucleus and pulvinar. Brain 125 (2), 350-360. http://dx.doi.org/10.1093/brain/awf032.

Karnath, H.O., Rorden, C., 2012. The anatomy of spatial neglect. Neuropsychologia 50 (6), 1010-1017. http://dx.doi.org/10.1016/j.neuropsychologia.2011.06.027.

Kim, Y.-H., Min, S.-J., Ko, M.-H., Park, J.-W., Jang, S.H., Lee, P.K., 2005. Facilitating visuospatial attention for the contralateral hemifield by repetitive TMS on the posterior parietal cortex. Neurosci. Lett. 382 (3), 280-285. http://dx.doi.org/ 10.1016/j.neulet.2005.03.043.

Kinsbourne, M., 1977. Hemi-neglect and hemisphere rivalry. Adv. Neurol. 18, 41-49.

Koch, G., Oliveri, M., Torriero, S., Caltagirone, C., 2005. Modulation of excitatory and inhibitory circuits for visual awareness in the human right parietal cortex. Exp. Brain Res. 160 (4), 510-516.

Marg, E., Rudiak, D., 1994. Phosphenes induced by magnetic stimulation over the occipital brain: description and probable site of stimulation. Optom. Vis. Sci. 71 (5), 301-311.

Meister, I., Wienemann, M., Buelte, D., Grünewald, C., Sparing, R., Dambeck, N., Boroojerdi, B., 2006. Hemiextinction induced by transcranial magnetic stimulation over the right temporo-parietal junction. Neuroscience 142 (1), 119-123. http://dx.doi.org/10.1016/j.neuroscience.2006.06.023.

Mesulam, M.M., 1981. A cortical network for directed attention and unilateral neglect. Ann. Neurol. 10 (4), 309-325.

Mesulam, M.M., 1999. Spatial attention and neglect: parietal, frontal and cingulate contributions to the mental representation and attentional targeting of salient extrapersonal events. Philos. Trans. R. Soc. Lond. Ser. B: Biol. Sci. 354 (1387), 1325-1346. http://dx.doi.org/10.1098/rstb.1999.0482.

Milner, A.D., McIntosh, R.D., 2005. The neurological basis of visual neglect. Curr. Opin. Neurol. 18 (6), 748-753.

Muggleton, N.G., Postma, P., Moutsopoulou, K., Nimmo-Smith, I., Marcel, A., Walsh, V., 2006. TMS over right posterior parietal cortex induces neglect in a scenebased frame of reference. Neuropsychologia 44 (7), 1222-1229. http://dx.doi. org/10.1016/j.neuropsychologia.2005.10.004.

Müri, R., Bühler, R., Heinemann, D., Mosimann, U., Felblinger, J., Schlaepfer, T., Hess, C., 2002. Hemispheric asymmetry in visuospatial attention assessed with transcranial magnetic stimulation. Exp. Brain Res. 143 (4), 426-430. http://dx. doi.org/10.1007/s00221-002-1009-9.

Pascual-Leone, A., Gomez-Tortosa, E., Grafman, J., Alway, D., Nichelli, P., Hallett, M. 1994. Induction of visual extinction by rapid-rate transcranial magnetic stimulation of parietal lobe. Neurology 44 (3 Part 1), 494-498.

Posner, M.I., 1980. Orienting of attention. Q. J. Exp. Psychol. 32 (1), 3-25. http://dx doi.org/10.1080/00335558008248231.

Posner, M.I., Snyder, C.R., Davidson, B.J., 1980. Attention and the detection of signals. J. Exp. Psychol.: Gen. 109 (2), 160. http://dx.doi.org/10.1037/0096-3445.109.2.160.

Posner, M.I., Walker, J.A., Friedrich, F.A., Rafal, R.D., 1987. How do the parietal lobes direct covert attention? Neuropsychologia 25 (1 Part 1), 135-145. http://dx.doi. org/10.1016/0028-3932(87)90049-2.

Reynolds, J.H., Chelazzi, L., 2004. Attentional modulation of visual processing. Annu. Rev. Neurosci. 27, 611-647. http://dx.doi.org/10.1146/annurev. neuro.26.041002.131039.

Reynolds, J.H., Heeger, D.J., 2009. The normalization model of attention. Neuron 61 (2), 168-185. http://dx.doi.org/10.1016/j.neuron.2009.01.002.

Riddoch, M.J., Rappaport, S.J., Humphreys, G.W., 2009. Extinction: a window into attentional competition. Prog. Brain Res. 176, 149-159. http://dx.doi.org/ 10.1016/S0079-6123(09)17619-7.

Robertson, I.H., 2001. Do We Need the "Lateral" in Unilateral Neglect? Spatially nonselective attention deficits in unilateral neglect and their implications for rehabilitation. NeuroImage 14 (1), S85-S90. http://dx.doi.org/10.1006/ nimg.2001.0838.

Romei, V., Gross, J., Thut, G., 2010. On the role of prestimulus alpha rhythms over occipito-parietal areas in visual input regulation: correlation or causation? J. Neurosci. 30 (25), 8692-8697. http://dx.doi.org/10.1523/JNEUROSCI.016010.2010.

Ruff, C.C., Bestmann, S., Blankenburg, F., Bjoertomt, O., Josephs, O., Weiskopf, N., Driver, J., 2008. Distinct causal influences of parietal versus frontal areas on human visual cortex: evidence from concurrent TMS-fMRI. Cereb. Cortex 18 
F. Duecker, A.T. Sack / Neuropsychologia 74 (2015) 21-29

29

(4), 817-827. http://dx.doi.org/10.1093/cercor/bhm128.

Ruff, C.C., Blankenburg, F., Bjoertomt, O., Bestmann, S., Freeman, E., Haynes, J.-D., Driver, J., 2006. Concurrent TMS-fMRI and psychophysics reveal frontal influences on human retinotopic visual cortex. Curr. Biol. 16 (15), 1479-1488. http: //dx.doi.org/10.1016/j.cub.2006.06.057.

Ruff, C.C., Blankenburg, F., Bjoertomt, O., Bestmann, S., Weiskopf, N., Driver, J., 2009. Hemispheric differences in frontal and parietal influences on human occipital cortex: direct confirmation with concurrent TMS-fMRI. J. Cognit. Neurosci. 21 (6), 1146-1161. http://dx.doi.org/10.1162/jocn.2009.21097.

Sauseng, P., Feldheim, J.F., Freunberger, R., Hummel, F.C., 2011. Right prefrontal TMS disrupts interregional anticipatory EEG alpha activity during shifting of visuospatial attention. Front. Psychol. 2, 241. http://dx.doi.org/10.3389/ fpsyg.2011.00241.

Sereno, M.I., Pitzalis, S., Martinez, A., 2001. Mapping of contralateral space in retinotopic coordinates by a parietal cortical area in humans. Science 294 (5545), 1350-1354. http://dx.doi.org/10.1126/science.1063695.

Silvanto, J., Lavie, N., Walsh, V., 2006. Stimulation of the human frontal eye fields modulates sensitivity of extrastriate visual cortex. J. Neurophysiol. 96 (2), 941-945. http://dx.doi.org/10.1152/jn.00015.2006.

Silvanto, J., Muggleton, N., Lavie, N., Walsh, V., 2009. The perceptual and functional consequences of parietal top-down modulation on the visual cortex. Cereb. Cortex 19 (2), 327-330. http://dx.doi.org/10.1093/cercor/bhn091.

Silver, M.A., Kastner, S., 2009. Topographic maps in human frontal and parietal cortex. Trends Cognit. Sci. 13 (11), 488-495. http://dx.doi.org/10.1016/j. tics.2009.08.005.

Smith, D.T., Jackson, S.R., Rorden, C., 2005. Transcranial magnetic stimulation of the left human frontal eye fields eliminates the cost of invalid endogenous cues. Neuropsychologia 43 (9), 1288-1296. http://dx.doi.org/10.1016/j. neuropsychologia.2004.12.003.

Sparing, R., Thimm, M., Hesse, M.D., Küst, J., Karbe, H., Fink, G.R., 2009. Bidirectional alterations of interhemispheric parietal balance by non-invasive cortical stimulation. Brain 132 (11), 3011-3020. http://dx.doi.org/10.1093/brain/awp154.

Suchan, J., Rorden, C., Karnath, H.-O., 2012. Neglect severity after left and right brain damage. Neuropsychologia 50 (6), 1136-1141. http://dx.doi.org/10.1016/j. neuropsychologia.2011.12.018.

Szczepanski, S.M., Kastner, S., 2013. Shifting attentional priorities: control of spatial attention through hemispheric competition. J. Neurosci. 33 (12), 5411-5421. http://dx.doi.org/10.1523/JNEUROSCI.4089-12.2013.

Taylor, P.C.J., Nobre, A.C., Rushworth, M.F.S., 2007. FEF TMS affects visual cortical activity. Cereb. Cortex 17 (2), 391-399. http://dx.doi.org/10.1093/cercor/bhj156.

Taylor, P.C.J., Thut, G., 2012. Brain activity underlying visual perception and attention as inferred from TMS-EEG: a review. Brain Stimul. 5 (2), 124-129. http: //dx.doi.org/10.1016/j.brs.2012.03.003.

Thut, G., Nietzel, A., Pascual-Leone, A., 2005. Dorsal posterior parietal rTMS affects voluntary orienting of visuospatial attention. Cereb. Cortex 15 (5), 628-638. http://dx.doi.org/10.1093/cercor/bhh164.

Thut, G., Veniero, D., Romei, V., Miniussi, C., Schyns, P., Gross, J., 2011. Rhythmic TMS causes local entrainment of natural oscillatory signatures. Curr. Biol. 21 (14), 1176-1185. http://dx.doi.org/10.1016/j.cub.2011.05.049.

Ungerleider, L.G., Kastner, S., 2000. Mechanisms of visual attention in the human cortex. Annu. Rev. Neurosci. 23 (1), 315-341. http://dx.doi.org/10.1146/annurev. neuro.23.1.315.

Vossel, S., Eschenbeck, P., Weiss, P., Weidner, R., Saliger, J., Karbe, H., Fink, G., 2011. Visual extinction in relation to visuospatial neglect after right-hemispheric stroke: quantitative assessment and statistical lesion-symptom mapping. J. Neurol. Neurosurg. Psychiatry 82 (8), 862-868. http://dx.doi.org/10.1136/ jnnp.2010.224261. 